\title{
COMPARING THE EFFECTS OF SUCROSE AND HIGH-FRUCTOSE CORN SYRUP ON LIPID METABOLISM AND THE RISK OF CARDIOVASCULAR DISEASE IN MALE RATS
}

\author{
Joanna Sadowska ${ }^{\bowtie}$, Magda Bruszkowska \\ Department of Human Nutrition Physiology, West Pomeranian University of Technology in Szczecin \\ Papieża Pawła VI 3, 71-459 Szczecin, Poland
}

\begin{abstract}
Background. The objective of this study was to compare, in an animal model, the effect of different sugar types (sucrose vs. high-fructose corn syrup 55\%) consumed as $10 \%$ by weight of the diet ( $11.6 \%$ of daily caloric intake) on the amount of food consumed, body weight, fatty tissue deposits, concentrations of selected lipids, and atherogenic indices of blood plasma.

Material and method. The experiment was carried out on 30 5-month-old Wistar male rats, fed three different diets, containing, amongst other foods, (1) ground unrefined cereal grains, (2) sucrose, (3) high-fructose corn syrup.

Results. Weight gains in animals on sucrose or high-fructose corn syrup diets were higher than those consuming basic feed, but the effect was not associated with perivisceral fat accumulation. It has been found that all the atherogenic indices (Castelli's Risk Index I, Castelli's Risk Index II, Atherogenic Index of Plasma, Atherogenic Coefficient) were statistically significantly higher in animals on a high-fructose corn syrup diet compared to both the control group and those on a sucrose diet.

Conclusion. The effect of the 55\% high-fructose corn syrup on the tested parameters of lipid metabolism was not equivalent to that of sucrose. Using HFCS-55 instead of sucrose has an adverse effect on blood lipid parameters, while weight gains and peri-organ fat deposits are comparable. Moreover, the obtained results confirm that tested animals were susceptible to the adverse effects of sugars added to their diet, even in small amounts. This emphasises the need to precisely control the amount of added sugars in the diet.
\end{abstract}

Keywords: sucrose, high-fructose corn syrup, lipid metabolism, atherogenic indices of plasma

\section{INTRODUCTION}

Cardiovascular diseases (CVD) are the primary cause of premature deaths, particularly in developing countries. Blood lipid disorders, including low levels of high density lipoprotein cholesterol (HDL-C) and high levels of triacylgycerols (TG) and low density lipoprotein cholesterol (LDL-C), constitute a crucial risk factor for CVD (Yusuf et al., 2004; Weissglas-Volkov and Pajukanta, 2010). The adverse changes in blood lipid parameters may result from excessive consumption of monosaccharides and disaccharides (Yang et al., 2014), which are added more and more frequently to foodstuffs for technology and flavour purposes. Therefore, the Institute of Medicine recommended in 2002 that added sugars should not exceed $25 \%$ of daily caloric intake (Institute of Medicine, 2002). In 2003, the World Health Organisation recommended that added 
sugar should not exceed $10 \%$ of the daily discretionary calorie allowance (WHO, 2003), and at present the American Heart Association recommends limiting the amount of added sugar consumed to no more than 100 calories per day for women and 150 calories per day for men, which equates to about $5 \%$ of the daily discretionary calorie allowance (Vos et al., 2016). But for most of the population meeting these requirements seems to be impossible.

The objective of this study was to compare, in an animal model, the effect of different sugar types (sucrose vs. high-fructose corn syrup 55\%) consumed as $10 \%$ by weight of the diet ( $11.6 \%$ of daily caloric intake) on the amount of food consumed, body weight, fatty tissue deposits, concentrations of selected lipids, and atherogenic indices of blood plasma.

\section{MATERIAL AND METHOD}

\section{Material}

The experiment was conducted on 30 5-month-old Wistar male rats, of initial body weight $398 \pm 32.6 \mathrm{~g}$. The rats were obtained from the animal husbandry of Chair and Department of Toxicology, Poznań University of Medical Sciences, Poland. The research was approved by the Local Ethics Commission (Approval no. $1 / 2012$ ).

\section{Methods}

After a week-long conditioning phase on standard laboratory rat feed in the vivarium environment (temperature $21-22^{\circ} \mathrm{C}$, humidity $55-60 \%, 12 \mathrm{~h} / 12 \mathrm{~h}$ light/dark cycle), the animals were sorted into three equinumerous groups $(n=10)$ of similar average body weight (397 $\pm 33.1 \mathrm{~g}$ ), housed in individual cages, and fed ad libitum on pelleted feeds composed of the same components except for the varying components being tested, produced by the Feeds and Concentrates Plant in Kcynia, Poland. The procedure 5.14.5 "Cleaning of machines and devices" was implemented prior to the introduction of the feeds. Group I (CON) received the standard feed (Labofeed H), while group II (SUC) was fed modified feed 1, and group III (HFCS) modified feed 2. In modified feed $1,83.5 \%$ of the wheat was substituted with wheat flour, and $50 \%$ of the corn grain was substituted with sucrose (relative to the standard feed). In modified feed 2, sucrose was substituted with high-fructose corn syrup-55 (HFCS-55 is 55\% fructose, in powdered form). HFCS- $55 \%$ was selected because it contains more fructose (than HFCS-42), which causes adverse metabolic effects. HFCS-55 is added not only to beverages, but also to solid foods. Sucrose or HFCS accounted for $11.6 \%$ of the calories consumed. The proportions of the other components was unchanged (Table 1). All diets were based on the balanced modification of the AIN-93 diet formulation (Reeves et al., 1993). Changes of feed components were designed to reflect the changes taking place today in the composition of diets, which contain simple sugars and refined carbohydrates. The animals were provided with pure water to drink.

Experimental studies usually test diets comprised of $15-30 \%$ sugars, but still it is not known how an

Table 1. Component composition of feeds used in the experiment, $\mathrm{g} / 100 \mathrm{~g}$

\begin{tabular}{lccc}
\hline \multicolumn{1}{c}{ Component } & Basic feed & Modified feed 1 & Modified feed 2 \\
\hline 1 & 2 & 3 & 4 \\
\hline Wheat & 36.4 & 6 & 6 \\
Corn grain & 20 & 10 & 10 \\
Wheat bran & 20 & 20 & 20 \\
Dry whey & 3 & 3 & 3 \\
Fodder salt $(99 \% \mathrm{NaCl})$ & 0.3 & 0.3 & 0.3 \\
Soya-bean grain & 17 & 17 & 17 \\
Fodder chalk $\left(97 \% \mathrm{CaCO}_{3}\right)$ & 1.5 & 1.5 & 1.5 \\
\hline
\end{tabular}


Sadowska, J., Bruszkowska, M. (2017). Comparing the effects of sucrose and high-fructose corn syrup on lipid metabolism and the risk of cardiovascular disease in male rats. Acta Sci. Pol. Technol. Aliment., 16(2), 231-240. http://dx.doi.org/10.17306/J. AFS.2017.0482

Table 1 cont

\begin{tabular}{llcc}
\hline \multicolumn{1}{c}{1} & 2 & 3 & 4 \\
\hline Phosphate 2-CA $\left(\mathrm{CaHPO}_{4}\right)$ & 0.8 & 0.8 & 0.8 \\
Premix LRM & & 1 & 1 \\
Wheat flour & - & 30.4 & 30.4 \\
$\begin{array}{l}\text { Sucrose } \\
\begin{array}{l}\text { High fructose corn syrup-55 } \\
\text { (in powder) }\end{array}\end{array}$ & - & 10 & - \\
\hline
\end{tabular}

*Vitamin-mineral composition used in animals feeds content per kg: A - 1500000 IU, vit. D3 - $100000 \mathrm{IU}$; vit. E - $8000 \mathrm{mg}$, vit. K - $300 \mathrm{mg}$, vit. B1 - $1200 \mathrm{mg}$, vit. B2 - $1200 \mathrm{mg}$, vit. B6 - $1000 \mathrm{mg}$, vit. B12 - $8 \mathrm{mg}$, Se - $100 \mathrm{mg}, \mathrm{Fe}-16000 \mathrm{mg}$, $\mathrm{Mn}-4500 \mathrm{mg}, \mathrm{Zn}-6000 \mathrm{mg}, \mathrm{Cu}-1300 \mathrm{mg}, \mathrm{I}-100 \mathrm{mg}, \mathrm{Co}-200 \mathrm{mg}$.

increase in added sugars of $11-12 \%$ calorific intake, only slightly exceeding the recommended value $(10 \%)$, would change the tested parameters. Moreover, this study considers the type of sugar used, because sucrose is being replaced more and more frequently by high-fructose corn syrup (HFCS) (Bruhns, 2009), and its effect on the human body has not been determined unambiguously (Melanson et al., 2007; Stanhope and Havel, 2008). Compared to glucose, fructose exerts a more adverse effect on lipid metabolism, which has been confirmed in a number of studies (Chong et al., 2007; Schaefer et al., 2009; Vasankari and Vasankari, 2006). However, it is not known whether the small difference in fructose content between sucrose (50\% fructose) and HFCS-55 (55\% fructose) is sufficiently significant to alter the metabolism of lipids.

\section{Analyses}

The prepared diets were subjected to chemical analysis (AOAC, 2003) to determine the contents of total nitrogen (by Kjeldahl's method, on Kjeltec 2100 apparatus), converted to quantity of protein, crude fat (by Soxhlet's method, on Soxtec 1046 apparatus), dry matter (by a gravimetric method), ash (by a gravimetric method) and fibre (in an ANKOM 220 apparatus). The digested carbohydrate content was calculated from the difference between dry matter and the sum of the other solid dietary components. The metabolisable energy was calculated using commonly applied energy equivalents (Table 2): protein $-4.0 \mathrm{kcal} / \mathrm{g}$
$(16.76 \mathrm{~kJ} / \mathrm{g})$, fat $-9.0 \mathrm{kcal} / \mathrm{g}(37.71 \mathrm{~kJ} / \mathrm{g})$, digested carbohydrates $-4.0 \mathrm{kcal} / \mathrm{g}(16.76 \mathrm{~kJ} / \mathrm{g})$.

The experiment lasted for six weeks, the amount of feed consumed by the animals was recorded daily, and once a week the animals were weighed. The amount of feed consumed was calculated from the difference between the weight of the feed given to the feeder and mass of feed which was left in the feeder, plus that which fell to the bottom of the frame. On the completion of the experiment, the animals were fasted overnight (12 h) and anaesthetised with an intramuscular injection $(10 \mathrm{mg} / \mathrm{kg} \mathrm{m} . \mathrm{c}$.) of Ketanest (Pfizer Ireland Pharmaceuticals). Blood was sampled from the heart to tubes with anticoagulant and centrifuged, at $2000 \mathrm{~g}$ for $10 \mathrm{~min}$ at $4^{\circ} \mathrm{C}$ (MPW 350-R, MPW Med. instruments, Warsaw, Poland). Plasma samples were stored at $4^{\circ} \mathrm{C}$ and assayed within $24 \mathrm{~h}$.

Intraperitoneal and retroperitoneal fat was dissected out immediately after killing the rats, and weighed. Thigh muscles (triceps femoris) and livers were dissected and used to determine the percentage of crude fat, with the Soxhlet technique in Soxtec HT6 apparatus (Foss Tecator).

Blood plasma obtained after clot centrifugation was assayed for the concentration of triacylglycerols (biotest kit BioSystems ref. no. 11528), total cholesterol (biotest kit BioSystems ref. no. 11505), HDL-cholesterol (direct method, biotest kit BioSystems ref. no. 11557), LDL-cholesterol (biotest kit BioSystems ref. no. 11579) with the colorimetric method, on the Metertech spectrophotometer. 
Sadowska, J., Bruszkowska, M. (2017). Comparing the effects of sucrose and high-fructose corn syrup on lipid metabolism and the risk of cardiovascular disease in male rats. Acta Sci. Pol. Technol. Aliment., 16(2), 231-240. http://dx.doi.org/10.17306/J. AFS.2017.0482

Table 2. Chemical composition of feeds used in the experiment

\begin{tabular}{|c|c|c|c|}
\hline Component & Basic feed & Modified feed 1 & Modified feed 2 \\
\hline Total protein, $\%$ & $23.1 \pm 0.58^{\mathrm{a}}$ & $22.1 \pm 0.85^{\mathrm{a}}$ & $22.7 \pm 0.99^{\mathrm{a}}$ \\
\hline percentage of energy & 27.2 & 25.6 & 26.4 \\
\hline Crude fat, $\%$ & $2.76 \pm 0.07^{\mathrm{a}}$ & $2.90 \pm 0.14^{\mathrm{a}}$ & $2.82 \pm 0.12^{\mathrm{a}}$ \\
\hline percentage of energy & 7.3 & 7.6 & 7.4 \\
\hline \multicolumn{4}{|l|}{ Carbohydrates, $\%$} \\
\hline total & $60.1 \pm 0.48^{\mathrm{a}}$ & $61.9 \pm 0.51^{\mathrm{a}}$ & $60.1 \pm 0.62^{\mathrm{a}}$ \\
\hline fiber & $4.48 \pm 0.13^{\mathrm{b}}$ & $4.03 \pm 0.15^{\mathrm{a}}$ & $4.06 \pm 0.09^{\mathrm{a}}$ \\
\hline digested & $55.6 \pm 0.52^{\mathrm{a}}$ & $57.8 \pm 0.42^{\mathrm{b}}$ & $56.9 \pm 0.61^{\mathrm{b}}$ \\
\hline Percentage of energy & 65.4 & 67.0 & 66.1 \\
\hline Total ash, $\%$ & $6.03 \pm 0.14^{\mathrm{b}}$ & $5.77 \pm 0.27^{\mathrm{a}}$ & $5.52 \pm 0.10^{\mathrm{a}}$ \\
\hline Dry matter, \% & $92.0 \pm 0.12^{\mathrm{a}}$ & $92.6 \pm 0.19^{\mathrm{a}}$ & $92.0 \pm 0.11^{\mathrm{a}}$ \\
\hline \multicolumn{4}{|l|}{ Metabolizable energy } \\
\hline $\mathrm{kcal} \cdot \mathrm{g}^{-1}$ & $3.40 \pm 0,03^{\mathrm{a}}$ & $3.45 \pm 0,05^{\mathrm{b}}$ & $3.44 \pm 0,02^{\mathrm{b}}$ \\
\hline $\mathrm{kJ} \cdot \mathrm{g}^{-1}$ & $14.20 \pm 0,20^{\mathrm{a}}$ & $14.42 \pm 0,12^{\mathrm{b}}$ & $14.38 \pm 0,10^{\mathrm{b}}$ \\
\hline \multicolumn{4}{|c|}{ Percentage of energy from: } \\
\hline sugar added & 0 & 11.6 & 11.6 \\
\hline including fructose & 0 & 5.8 & 6.4 \\
\hline
\end{tabular}

The Atherogenic ratios were calculated as follows (da Luz et al., 2008; Dobiásová, 2004):

Castelli's Risk Index I (CRI-I) = $\mathrm{TC}[\mathrm{mmol} / \mathrm{L}] / \mathrm{HDL}-\mathrm{C}[\mathrm{mmol} / \mathrm{L}]$

Castelli's Risk Index II (CRI-II) = LDL-C [mmol/L] / HDL-C [mmol/L]

Atherogenic Index of Plasma (AIP) $=$ $\log \{\mathrm{TG}[\mathrm{mmol} / \mathrm{L}] / \mathrm{HDL}-\mathrm{C}[\mathrm{mmol} / \mathrm{L}]\}$

Atherogenic Coefficient $(\mathrm{AC})=$ $\{\mathrm{TC}[\mathrm{mmol} / \mathrm{L}]-\mathrm{HDL}-\mathrm{C}[\mathrm{mmol} / \mathrm{L}]\} /$ HDL-C [mmol/L]

\section{Statistics}

Biochemical data is shown as mean and standard deviation. The resulting data was tested for normality of distribution (Shapiro-Wilk test) and processed statistically by means of the Statistica software package, using the post hoc Duncan test at the significance level $\alpha=0.05$.

\section{RESULTS}

Analysing the results, it has been found that rats on the sucrose diet consumed significantly less food per $100 \mathrm{~g}$ of body weight, but the energy intake was comparable among all animal groups (11.84-12.27 MJ/6 weeks). Although the energy intake was comparable, weight gains in animals on sucrose or HFCS diet were statistically significantly higher, both in direct terms and per unit of energy intake (Table 3). The effect was not associated with perivisceral fat accumulation, with similar fat deposits being found in all the tested groups. The type of sugar affected muscle fat content, which was statistically significantly higher in animals on the sucrose diet $(3.54 \%)$ compared to the other animals (CON 2.41\%, HFCS 2.62\%). Moreover, liver fat was statistically significantly higher in animals on the sucrose diet $(2.73 \%)$ than in the control group $(2.51 \%)$, but comparable to that found in animals on the HFCS $\operatorname{diet}(2.57 \%)$. 
Sadowska, J., Bruszkowska, M. (2017). Comparing the effects of sucrose and high-fructose corn syrup on lipid metabolism and the risk of cardiovascular disease in male rats. Acta Sci. Pol. Technol. Aliment., 16(2), 231-240. http://dx.doi.org/10.17306/J. AFS.2017.0482

Table 3. Effect of diet type on feed and energy intake, body weight gain and amount and localization of fatty tissue in rats, $\overline{\mathrm{x}} \pm \mathrm{SD}, n=30$

\begin{tabular}{llll}
\hline \multicolumn{1}{c}{ Trait } & \multicolumn{1}{c}{ CON } & \multicolumn{1}{c}{ SUC } & HFCS \\
\hline Feed intake, g/6 weeks & $862 \pm 52.6^{\mathrm{a}}$ & $846 \pm 68.5^{\mathrm{a}}$ & $871 \pm 44.3^{\mathrm{a}}$ \\
Feed intake, g/100 g b.w. & $193 \pm 9.96^{\mathrm{b}}$ & $185 \pm 6.33^{\mathrm{a}}$ & $189 \pm 5.53^{\mathrm{b}}$ \\
Energy intake, MJ/6 weeks & $12.04 \pm 0.73^{\mathrm{a}}$ & $11.84 \pm 0.80^{\mathrm{a}}$ & $12.27 \pm 0.53^{\mathrm{a}}$ \\
Initial body weight, g & $398 \pm 36.9^{\mathrm{a}}$ & $399 \pm 31.9^{\mathrm{a}}$ & $397 \pm 30.2^{\mathrm{a}}$ \\
Final body weight, g & $447 \pm 42.1^{\mathrm{a}}$ & $457 \pm 37.0^{\mathrm{a}}$ & $460 \pm 31.5^{\mathrm{a}}$ \\
Body weight gain, g/100 g feed & $5.54 \pm 0.89^{\mathrm{a}}$ & $6.82 \pm 1.47^{\mathrm{b}}$ & $7.24 \pm 1.26^{\mathrm{b}}$ \\
Body weight gain, g/1000 kJ & $3.90 \pm 0.63^{\mathrm{a}}$ & $4.73 \pm 1.02^{\mathrm{b}}$ & $5.04 \pm 0.87^{\mathrm{b}}$ \\
Intraperitoneal fat, g/100 g b.w. & $0.779 \pm 0.190^{\mathrm{a}}$ & $0.787 \pm 0.118^{\mathrm{a}}$ & $0.724 \pm 0.074^{\mathrm{a}}$ \\
Intraperitoneal fat, g/1000 kJ & $0.288 \pm 0.074^{\mathrm{a}}$ & $0.296 \pm 0.048^{\mathrm{a}}$ & $0.267 \pm 0.051^{\mathrm{a}}$ \\
Retroperitoneal fat, g/100 g b.w. & $0.685 \pm 0.211^{\mathrm{a}}$ & $0.678 \pm 0.179^{\mathrm{a}}$ & $0.675 \pm 0.165^{\mathrm{a}}$ \\
Retroperitoneal fat, g/1000 kJ & $0.255 \pm 0.090^{\mathrm{a}}$ & $0.254 \pm 0.065^{\mathrm{a}}$ & $0.249 \pm 0.063^{\mathrm{a}}$ \\
Muscle fat, \% & $2.41 \pm 0.319^{\mathrm{a}}$ & $3.54 \pm 0.932^{\mathrm{b}}$ & $2.62 \pm 0.205^{\mathrm{a}}$ \\
Liver fat, \% & $2.51 \pm 0.214^{\mathrm{a}}$ & $2.73 \pm 0.138^{\mathrm{b}}$ & $2.57 \pm 0.194^{\mathrm{ab}}$ \\
\hline
\end{tabular}

a,b Means denoted different letters in the same line are statistically different, $p \leq 0.05$. b.w. - body weight.

A significantly higher plasma TG level was found in animals given added sugars, but TC and HDL-C levels were lower compared to the control group (Table 4).
The HDL-C level was the lowest in animals on HFCS $(0.536 \mathrm{mmol} / \mathrm{L})$, which resulted in a significantly higher Castelli's risk index-I (5.10 vs. 3.44-3.84). It

Table 4. Effect of diet type on triacylglycelors and cholesterol level and chosen atherogenic indices in plasma of examined rats, $\overline{\mathrm{x}} \pm \mathrm{SD}, n=30$

\begin{tabular}{lrrr}
\hline \multicolumn{1}{c}{ Trait } & \multicolumn{1}{c}{ CON } & \multicolumn{1}{c}{ SUC } & \multicolumn{1}{c}{ HFCS } \\
\hline Triacyloglycerols, mmol/L & $0.243 \pm 0.094^{\mathrm{a}}$ & $0.375 \pm 0.138^{\mathrm{b}}$ & $0.340 \pm 0.097^{\mathrm{b}}$ \\
Total cholesterol, mmol/L & $3.37 \pm 0.64^{\mathrm{b}}$ & $3.06 \pm 0.55^{\mathrm{ab}}$ & $2.67 \pm 0.43^{\mathrm{a}}$ \\
HDL-C, mmol/L & $0.982 \pm 0.084^{\mathrm{c}}$ & $0.790 \pm 0.097^{\mathrm{b}}$ & $0.536 \pm 0.078^{\mathrm{a}}$ \\
LDL-C, mmol/L & $1.03 \pm 0.183^{\mathrm{a}}$ & $1.05 \pm 0.207^{\mathrm{a}}$ & $1.07 \pm 0.163^{\mathrm{a}}$ \\
CR-I & $3.44 \pm 0.72^{\mathrm{a}}$ & $3.85 \pm 0.45^{\mathrm{a}}$ & $5.10 \pm 1.13^{\mathrm{b}}$ \\
CR-II & $1.046 \pm 0.148^{\mathrm{a}}$ & $1.327 \pm 0.183^{\mathrm{b}}$ & $2.018 \pm 0.325^{\mathrm{c}}$ \\
AC & $2.44 \pm 0.718^{\mathrm{a}}$ & $2.845 \pm 0.448^{\mathrm{a}}$ & $4.098 \pm 1.131^{\mathrm{b}}$ \\
AIP & $-0.637 \pm 0.159^{\mathrm{a}}$ & $-0.347 \pm 0.129^{\mathrm{b}}$ & $-0.207 \pm 0.111^{\mathrm{c}}$ \\
\hline
\end{tabular}

${ }^{a-c}$ Means denoted different letters in the same line are statistically different, $p \leq 0.05$. 
has been found that all the atherogenic indices (CR-I, CR-II, AIP, AC) were statistically significantly higher in animals on the HFCS diet compared to both the control group and those on sucrose diet.

\section{DISCUSSION}

In this study, food intake per $100 \mathrm{~g}$ of body weight was lower in animals consuming added sugars compared to the control group, but only the effect of sucrose was statistically significant. Similar results were obtained by Tsanzi et al. (2008) and Light et al. (2009) who found that food intake in animals on a sucrose diet was lower compared to those on HFCS-55 diet. The glycemic index (GI) is regarded as one of the most significant factors affecting food consumption. Taking the GI value into account, 65 for sucrose and 73 for HFCS-55 (Segal et al., 2007), it may be assumed that the slightly higher food intake in the group on the HFCS-55 diet could result from elevated blood glucose level after feeding, which in turn was followed by hypoglycaemia that promoted excessive food intake (Ludwig, 2002). Also, a lower energetic reserve, related to a lower amount of fatty tissue, could cause increased appetite in animals on an HFCS-55 diet compared to animals on a sucrose diet, in which slightly higher perivisceral fat deposits were found, as well as higher levels of muscle fat. One of the arguments against the use of HFCS is its potential ability to affect insulin and leptin levels, as fructose, unlike glucose, does not stimulate the secretion of insulin and leptin, and may increase the intake of food.

However, the energy intake was comparable in animals from all the tested groups. These results are in accordance with findings of Roy et al. (2003), and show that, in animals, meeting energetic needs is of paramount importance in regulating food intake. Studies based on animal models eliminate the effect of emotional factors, which significantly influence food intake in human subjects. People often eat to satisfy their psychological needs, such as the desire to feel good or to relieve emotional stress, rather than because of being actually hungry. Moreover, social and cultural aspects are of vital importance as well (Bellisle, 2003).

It has been found that the amount of added sugars had a significant effect on body weight gains in the tested animals, regardless of sugar type. Similar results were obtained by Light et al. (2009) and Tsanzi et al. (2008). In contrast, Bocarsly et al. (2010) observed higher weight gains in animals on an HFCS diet than animals on a sucrose diet. However, it should be noted that they provided sugars in a liquid form, which could alter the rate of monosacharide absorption from HFCS, increase the GI index, stimulate insulin release, and, as a consequence, result in a higher accumulation of fatty tissue.

No differences in the amount of epicardial and perivisceral fatty tissue were found among the tested groups. Also, studies carried out by Light et al. (2009) did not reveal any statistically significant differences in fat deposits around gonads or in the retroperitoneal region between the groups provided with HFCS-55 or sucrose.

Lower muscle fat content was observed in animals fed HFCS compared to those fed sucrose. Chong et al. (2007) showed that eating a meal with fructose, which predominates in the diet of HFCS-fed animals, reduces the activity of lipoprotein lipase, and impaired catabolism of TG (present in VLDL) hinders tissue fat synthesis.

Animals fed added sugars, regardless of sugar type, had higher plasma TG levels. The effect of HFCS and sucrose on the TG level was also reported by Akar et al. (2012) in animals, and by Stanhope et al. (2015) in human subjects. The plasma TG level reflects the amount and type of VLDL in the blood, and indicates their enhanced biosynthesis in the liver and/or reduced clearance from the blood. A number of studies have shown that increased consumption of fructose significantly elevates the rate of lipogenesis, accelerates esterification of fatty acids, and promotes VLDL secretion. The effect is enhanced by the increase in dietary fructose. However, such an effect was not observed in this study. Due to higher VLDL levels, in quantitative terms, there is also more apoC-III and apoC-I formed in the liver (Cooper, 1987; van Capelleveen et al., 2017). The apoproteins inhibit the activity of lipoprotein lipase (C-III) and decrease binding of lipoprotein particles to hepatic receptors (C-I), which in turn delays VLDL clearance from plasma. Moreover, apoC-III plays a crucial role in converting VLDL2 (small, TG-poor) into VLDL3 (big, TG-rich) (Sundaram et al., 2010; Qin et al., 2011). 
In this study, in animals fed sucrose and HFCS solutions, TG levels were similar. The opposite results were obtained by Bocarsly et al. (2010) who reported higher TG levels in the blood of male rats fed the HFCS-55 solution compared to the ones on sucrose. But Stanhope et al. (2008) and Yu et al. (2013) did not report any differences in the plasma TG level among humans on sucrose or HFCS-55.

This study has not confirmed that sugar type has any effect on blood cholesterol and its LDL fraction. Also Akar et al. (2012), Light et al. (2009) and Lowndes et al. (2014) did not observe any effect resulting from HFCS on the TC level in animal and human subjects. However, it may be observed in the study conducted by Lowndes et al. (2012) that the HDL-C level was lower in people on HFCS-55 compared to those who consumed exactly the same amount of sucrose. Similarly, Bravo et al. (2013) found lower plasma levels of HDL-C in people on HFCS-55 compared to those on sucrose, although the difference was not statistically significant. Opposite results were reported by Figlewicz et al. (2009) and Ferder et al. (2010).

In this study, the effect of added sugars was reflected in a significantly lower plasma HDL-C level in tested animals, and the effect of HFCS in that regard was stronger than that of sucrose. A low HDL-C level, indicating lower blood HDL, which act as antioxidants due to the presence in their particles of AI apoproteins and enzymes such as paraoxonase and the plateletactivating factor acetylhydrolase. In a diet containing fructose, the low HDL level has a particularly adverse effect, because fructose metabolism induces oxidative stress in rats (Girard et al., 2006).

The lipid profile, drawn in routine biochemical tests, includes levels of TG, TC, and the cholesterol fractions HDL-C and LDL-C, which allows the risk of coronary heart disease (CAD) to be predicted through the calculation of the atherogenic index of plasma (AIP). The Framingham Heart Study revealed that abnormal values in the lipid profile play a role in developing CAD, mainly due to the high level of LDL-C (Castelli et al., 1992). Later, CAD was found to be associated with hypertriglyceridemia and decreased HDL-C level (Brunzell, 2007), the latter being considered an independent CAD risk factor (Von Eckardstein et al., 2001).
In this study, LDL-C levels did not differ among the groups of animals, but the groups differed in their levels of TG, TC and HDL-C. Bhardwaj et al. (2013) showed that the risk of atherogenesis increases when TG and HDL-C levels change, even when TC and LDL-C levels are comparable. In order to assess the CVD risk in this study, the following atherogenic markers were applied: CR-I, CR-II, AIP, and AC, which have been proven to be very useful in estimating the CVD risk when LDL-C levels are similar.

The computed CR-I and CR-II values were significantly higher in animals on an HFCS diet. It has been reported that CR-I and CR-II values have an effect on forming atherosclerotic plaque in coronary vessels and coronary events (Nair et al., 2009). Also elevated AIP values, resulting from high VLDL levels, are a risk factor for the incidence of cardiovascular disease, due to the increased risk of atherogenesis (Taylan and Tuncel, 2016). AIP is a very sensitive marker showing differences in lipoprotein proportions.

The atherogenic coefficient (AC) is a measure of the amount of non-HDL cholesterol in VLDL, IDL and LDL compared to the amount of cholesterol in $\mathrm{HDL}$, and it reflects the atherogenic potential of all plasma lipoprotein fractions. The importance of nonHDL-C in predicting the risk of atherosclerosis was experimentally shown to be comparable to the effect of Apo-B (Hermans et al., 2011). In this study, the AC index was significantly higher in animals on an HFCS diet compared to the control group and sucrose-fed group.

Having computed all the atherogenic indices, it has been found that they were highest in animals on an HFCS diet compared to the control group and sucrose-fed group. In the sucrose-fed group, AIP and CR-II were higher than in the control group. The difference in the amount of fructose derived from sucrose or HFCS was just $10.3 \%$ (5.8\% vs. $6.4 \%)$, but the observed differences in HDL-C levels indicate that even such a slight difference may have an adverse effect on blood lipid parameters and increase directly the risk of CVD, without affecting perivisceral fat deposits. Moreover, the obtained results show that $11.6 \%$ of added sugars in the daily caloric intake alters the lipid profile in an atherogenic direction, with the effect of HFCS being stronger than that of sucrose. 


\section{CONCLUSIONS}

The HFCS-55 effect on the tested parameters of lipid metabolism was not equivalent to that of sucrose. Using HFCS-55 instead of sucrose has an adverse effect on blood lipid parameters, while weight gains and peri-organ fat deposition are comparable. Moreover, the obtained results confirm that tested animals were susceptible to the adverse effects of sugars added to their diet in small amounts. This emphasises the need to precisely control the amount of added sugars in the diet.

\section{REFERENCES}

Akar, F., Uludağ, O., Aydın, A., Aytekin, Y. A., Elbeg, S., Tuzcu, M., Sahin, K. (2012). High-fructose corn syrup causes vascular dysfunction associated with metabolic disturbance in rats: protective effect of resveratrol. Food Chem. Toxicol., 50(6), 2135-2141. http://dx.doi. org/10.1016/j.fct.2012.03.061

AOAC. (2003). Official methods of analysis. $17^{\text {th }}$ ed. Gaithersburg: Association of Official Analytical and Chemists.

Bellisle, F. (2003). Why should we study human food intake behaviour? Nutr. Metab. Cardiovasc. Dis., 13(4), 189-193.

Bhardwaj, S., Bhattacharjee, J., Bhatnagar, M. K., Tyagi, S. (2013). Atherogenic index of plasma, Castelli Risk Index and Atherogenic Coefficient- new parameters in assessing cardiovascular risk. Int. J. Pharm. Bio. Sci., 3(3), 359-364.

Bocarsly, M. E., Powell, E. S., Avena, N. M., Hoebel, B. G. (2010). High-fructose corn syrup causes characteristics of obesity in rats: Increased body weight, body fat and triglyceride levels. Pharmacol. Biochem. Behav., 97(1), 101-106. http://dx.doi.org/10.1016/j.pbb.2010.02.012

Bravo, S., Lowndes, J., Sinnett, S., Yu, Z., Rippe, J. (2013). Consumption of sucrose and high-fructose corn syrup does not increase liver fat or ectopic fat deposition in muscles. Appl. Physiol. Nutr. Metab., 38(6), 681-688. http://dx.doi.org/10.1139/apnm-2012-0322

Bruhns, J. (2009). The reform of the EU sugar regime and its effects on the industry. Sugar J., 71(11), 13-16.

Brunzell, D. J. (2007). Hypertriglyceridemia. N. Engl. J. Med., 357, 1009-1017. http://dx.doi.org/10.1056/ NEJMcp070061

Castelli, W. P., Anderson, K., Wilson, P. W., Levy, D. (1992). Lipids and risk of coronary heart disease. The Framingham study. Ann. Epidemiol., 2(1-2), 23-28.
Chong, M. F., Fielding, B. A., Frayn, K. N. (2007). Mechanisms for the acute effect of fructose on postprandial lipemia. Am. J. Clin. Nutr., 85(6), 1511-1520.

Cooper, A. D. (1997). Hepatic uptake of chylomicron remnants. J. Lipid. Res., 38(11), 2173-2192.

da Luz, P. L., Favarato, D., Faria-Neto, J. R. Jr, Lemos, P., Chagas, A. C. (2008). High ratio of triglycerides to HDL-cholesterol predicts extensive coronary disease. Clinics (Sao Paulo), 63(4), 427-432.

Dobiásová, M. (2004). Atherogenic index of plasma [log (triglycerides/HDL-cholesterol)]: Theoretical and practical implications. Clin. Chem., 50(7), 1113-1115.

Ferder, L., Ferder, M. D., Inserra, F. (2010). The role of high-fructose corn syrup in metabolic syndrome and hypertension. Curr. Hypertens. Rep., 12(2), 105-112. http://dx.doi.org/10.1007/s11906-010-0097-3

Figlewicz, D. P., Ioannou, G., Bennett Jay, J., Kittleson, S., Savard, C., Roth, C. L. (2009). Effect of moderate intake of sweeteners on metabolic health in the rat. Physiol. Behav., 98(5), 618-624. http://dx.doi.org/10.1016/j. physbeh.2009.09.016

Girard, A., Madani, S., Boukortt, F., Cherkaoui-Malki, M., Belleville, J., Prost, J. (2006). Fructose-enriched diet modifies antioxidant status and lipid metabolism in spontaneously hypertensive rats. Nutrition, 22(7-8), 758-766.

Hermans, M. P., Sacks, F. M., Ahn, S. A., Rousseau, M. F. (2011). Non-HDL-cholesterol as valid surrogate to apolipoprotein B100 measurement in diabetes: Discriminant Ratio and unbiased equivalence. Cardiovasc. Diabetol., 28(10), 20. http://dx.doi.org/10.1186/1475-2840-10-20

Institute of Medicine. (2002). Dietary reference intakes for energy, carbohydrate, fiber, fat, fatty acids, cholesterol, protein, and amino acids. Washington: The National Academies Press.

Light, H. R., Tsanzi, E., Gigliotti, J., Morgan, K., Tou, J. C. (2009). The type of caloric sweetener added to water influences weight gain, fat mass, and reproduction in growing Sprague-Dawley female rats. Exp. Biol. Med. (Maywood), 234(6), 651-661.

Lowndes, J., Kawiecki, D., Pardo, S., Nguyen, V., Melanson, K. J., Yu, Z., Rippe, J. M. (2012). The effects of four hypocaloric diets containing different levels of sucrose or high-fructose corn syrup on weight loss and related parameters. Nutr. J., 11(55). http://dx.doi. org/10.1186/1475-2891-11-55

Lowndes, J., Sinnett, S., Pardo, S., Nguyen, V. T., Melanson, K. J., Yu, Z., ..., Rippe, J. M. (2014). The effect of normally consumed amounts of sucrose or highfructose corn syrup on lipid profiles, body composition 
Sadowska, J., Bruszkowska, M. (2017). Comparing the effects of sucrose and high-fructose corn syrup on lipid metabolism and the risk of cardiovascular disease in male rats. Acta Sci. Pol. Technol. Aliment., 16(2), 231-240. http://dx.doi.org/10.17306/J. AFS.2017.0482

and related parameters in overweight/obese subjects. Nutrients, 6(3), 1128-1144. http://dx.doi.org/10.3390/ nu6031128

Ludwig, D. S. (2002). The glycemic index. Physiological mechanisms relating to obesity, diabetes and cardiovascular disease. JAMA, 287(18), 2414-2423.

Melanson, K. J., Zukley, L., Lowndes, J., Nguyen, V., Angelopoulos, T. J., Rippe, J. M. (2007). Effects of highfructose corn syrup and sucrose consumption on circulating glucose, insulin, leptin, and ghrelin and on appetite in normal-weight women. Nutrition, 23(2), 103-112.

Nair, D., Carrigan, T. P., Curtin, R. J., Popovic, Z. B., Kuzmiak, S., Schoenhagen, P., ..., Desai, M. Y. (2009). Association of total cholesterol/ high-density lipoprotein cholesterol ratio with proximal coronary atherosclerosis detected by multislice computed tomography. Prev. Cardiol., 12(1), 19-26.

Qin, W., Sundaram, M., Wang, Y., Zhou, H., Zhong, S., Chang, C. C., ..., Yao, Z. (2011). Missense mutation in APOC3 within the $\mathrm{C}$-terminal lipid binding domain of human ApoC-III results in impaired assembly and secretion of triacylglycerol-rich very low density lipoproteins: evidence that ApoC-III plays a major role in the formation of lipid precursors within the microsomal lumen. J. Biol. Chem., 286(31), 27769-27780. http:// dx.doi.org/10.1074/jbc.M110.203679

Reeves, P. G., Nielsen, F. H., Fahey, G. C. (1993). AIN-93 purified diets for laboratory rodents: final report of the American Institute of Nutrition ad hoc writing committee on the reformulation of the AIN-76 rodent diet. J. Nutr., 123, 1939-1951.

Roy, H. J., Keenan, M. J., Zablah-Pimentel, E., Hegsted, M., Bulot, L., O’Neil, C. E., ..., Fernandez, J. M. (2003). Adult female rats defend "appropriate" energy intake after adaptation to dietary energy. Obes. Res., 11(10), 1214-1222. http://dx.doi.org/10.1038/oby.2003.167

Schaefer, E. J., Gleason, J. A., Dansinger, M. L. (2009). Dietary fructose and glucose differentially affect lipid and glucose homeostasis. J. Nutr., 139(6), 1257S-1262S. http://dx.doi.org/10.3945/jn.108.098186

Segal, M. S., Gollub, E., Johnson, R. J. (2007). Is the fructose index more relevant with regards to cardiovascular disease than glycemic index? Eur. J. Nutr., 46(7), 406417. http://dx.doi.org/10.1007/s00394-007-0680-9

Stanhope, K. L., Griffen, S. C., Bair, B. R., Swarbrick, M. M., Keim, N. L., Havel, P. J. (2008). Twenty-four-hour endocrine and metabolic profiles following consumption of high-fructose corn syrup-, sucrose-, fructose-, and glucose-sweetened beverages with meals. Am. J. Clin. Nutr., 87(5), 1194-1203.
Stanhope, K. L., Havel, P. J. (2008). Endocrine and metabolic effects of consuming beverages sweetened with fructose, glucose, sucrose, or high-fructose corn syrup. Am. J. Clin. Nutr., 88(6), 1733S-1737S. http://dx.doi. org/10.3945/ajen.2008.25825D

Stanhope, K. L., Medici, V., A Bremer, A. A., Lee V., Lam, H. D., Nunez, M. V., ..., Havel, P. J. (2015). A doseresponse study of consuming high-fructose corn syrupsweetened beverages on lipid/lipoprotein risk factors for cardiovascular disease in young adults. Am. J. Clin. Nutr., 101(6), 1144-1154. http://dx.doi.org/10.3945/ ajcn.114.100461

Sundaram, M., Zhong, S., Bou Khalil, M., Zhou, H., Jiang, Z. G., Zhao, Y., ..., Yao, Z. (2010). Functional analysis of the missense APOC3 mutation Ala23Thr associated with human hypotriglyceridemia. J. Lipid. Res., 51(6), 1524-1534. http://dx.doi.org/10.1194/jlr.M005108

Taylan, E., Tuncel, E. P. (2016). Distribution of LDL subgroups in patients with hyperlipidemia. Turk. J. Med. Sci., 46(2), 374-380. http://dx.doi.org/10.3906/ sag-1410-40

Tsanzi, E., Light, H. R., Tou, J. C. (2008). The effect of feeding different sugar-sweetened beverages to growing female Sprague-Dawley rats on bone mass and strength. Bone, 42(5), 960-968. http://dx.doi.org/10.1016/j.bone. 2008.01.020

van Capelleveen, J. C., Bernelot Moens, S. J., Yang, X., Kastelein, J. J. P., Wareham, N. J., Zwinderman, A. H., ..., Tsimikas, S. (2017). Apolipoprotein C-III levels and incident coronary artery disease risk: The EPIC-Norfolk prospective population study. Arterioscler. Thromb. Vasc. Biol., 37(6), 1206-1212. http://dx.doi. org/10.1161/ATVBAHA.117.309007

Vasankari, T. J., Vasankari, T. M. (2006). Effect of dietary fructose on lipid metabolism, body weight and glucose tolerance in humans. Scand. J. Food Nutr., 50(2), 55-63 http://dx.doi.org/10.1080/17482970600783356

Von Eckardstein, A., Nofer, J. R., Assmann, G. (2001). High density lipoproteins and arteriosclerosis: Role of cholesterol efflux and reverse cholesterol transport. Arterioscler. Thromb. Vasc. Biol., 21(1), 13-27.

Vos, M. B., Kaar, J. L., Welsh, J. A., Van Horn, L. V., Feig, D. I., Anderson, C. A., ..., Johnson, R. K. (2016). Added Sugars and Cardiovascular Disease Risk in Children: A scientific statement from the American Heart Association. Circulation, 134:00-00. http://dx.doi.org/10.1161/ CIR.0000000000000439

Weissglas-Volkov, D., Pajukanta, P. (2010). Genetic causes of high and low serum HDL cholesterol. J. Lip. Res., 51(8), 2032-2057. http://dx.doi.org/10.1194/jlr.R004739 
Sadowska, J., Bruszkowska, M. (2017). Comparing the effects of sucrose and high-fructose corn syrup on lipid metabolism and the risk of cardiovascular disease in male rats. Acta Sci. Pol. Technol. Aliment., 16(2), 231-240. http://dx.doi.org/10.17306/J. AFS.2017.0482

WHO. (2003). Diet, nutrition and the prevention of chronic diseases: report of a Joint WHO/FAO Expert Consultation. WHO Technical Report Series, No. 916. Geneva: World Health Organization.

Yang, Q., Zhang, Z., Gregg, E. W., Flanders, W. D., Merritt, R., Hu, F. B. (2014). Added sugar intake and cardiovascular diseases mortality among US adults. JAMA Int. Med., 174(4), 516-524. http://dx.doi.org/10.1001/ jamainternmed.2013.13563

Yu, Z., Lowndes, J., Rippe, J. (2013). High-fructose corn syrup and sucrose have equivalent effects on energy-regulating hormones at normal human consumption levels. Nutr. Res., 33(12), 1043-1052. http://dx.doi. org/10.1016/j.nutres.2013.07.020

Yusuf, S., Hawken, S., Ounpuu, S., Dans, T., Avezum, A., Lanas, F., ..., Lisheng, L. (2004). INTERHEART Study Investigators. Effect of potentially modifiable risk factors associated with myocardial infarction in 52 countries (the INTERHEART study): case-control study. Lancet, 364(9438), 937-952. http://dx.doi.org/10.1016/ S0140-6736(04)17018-9 